\title{
The histochemical localization of prostaglandin synthetase activity in reproductive tract of the male rat*
}

\author{
J. M. Johnson and L. C. Ellis \\ Department of Biology, Utah State University, Logan, Utah 84322, U.S.A.
}

\begin{abstract}
Summary. PG synthetase activity was assessed histochemically in the reproductive tract of male rats. Moderate activity was observed in tails of spermatozoa within the corpus and cauda epididymidis but there was no activity in the caput epididymidis or the seminiferous tubules. The sperm tail activity was maximal for cells within the vas deferens. PG synthetase activity was also observed in individual adipose cells adhering to the testicular capsule, epididymis and vas deferens, and in isolated interstitial cells of the testis and the caput, corpus and cauda epididymidis. Specific cells in the capsules of the testes, epididymis and vas deferens also produced PGs. The activity observed in the interstitial cells of the testis and the caput epididymidis was less than that for the other tissues in terms of the proportion of possible cells. The demonstration of PG synthetase activity paralleled the known loss of arachidonic acid from the phospholipids of the spermatozoa as they pass through the male tract. Endogenous substrate was not limiting in the assay system, even in the testis and caput epididymidis where PG synthesis was not normally observed, indicating that a PG synthesis inhibitor may be present in these two tissues. PG synthetase activity within teased seminiferous tubules was markedly increased by physical trauma. Indomethacin diminished but did not eliminate synthesis.
\end{abstract}

\section{Introduction}

Several prostaglandins (PGs) have been isolated from human seminal plasma (Sasamori, 1965; Hamberg \& Samuelsson, 1966; Bygdeman \& Samuelsson, 1966; Bygdeman, Svanborg \& Samuelsson, 1969) and have been found in the seminal plasma of the rabbit (Sorgen \& Glass, 1972), bull (Voglmayr, 1973), ram (Poulos, Brown-Woodman, White \& Cox, 1975) and mouse (Badr, Barcikowski \& Bartke, 1975). Clinical evidence suggests that certain PGs are important for normal fertility (Hawkins, 1967; Bygdeman, 1969; Brummer \& Gillespie, 1972). Hawkins (1967) found a general reduction of all PGs in infertile males, and reported the level of PGs to be directly proportional to sperm density. Bygdeman (1969) reported lesser amounts of PGE-1 in the semen of human males who were functionally infertile compared to males of proven fertility.

Neill \& Masters (1972) identified arachidonic acid, a PG precursor, as a major component of sperm lipids. In 1973, Poulos, Voglmayr \& White reported that the phospholipid-linked, fatty acid acid pattern of bull spermatozoa showed that relatively large amounts of arachidonic acid, which could function in PG synthesis, were lost from the spermatozoa during their passage through the epididymis. Another study showed that ram spermatozoa (Poulos et al., 1975) lose large amounts of arachidonic acid as they move through the male reproductive tract. Similarly, Arora, Dinaker \& Prasad (1975) reported a drop in the arachidonic-acid containing lipids of spermatozoa as they pass through the epididymis of the rhesus monkey. Poulos et al. (1975) and Marley \& Smith (1975) suggested that spermatozoa may be the source of seminal PGs. It had been previously suggested (Poulos et al., 1973) that PGs may play a functional role in the maturation process (motility and fertilization ability) of spermatozoa and in their transport through the male reproductive system. Reports of the inability of spermatozoa from the testis or caput epididymidis of the bull (Nishikawa \& Waide, 1952; Amann \& Griel, 1974), ram (Setchell, Scott, Voglmayr \& Waites, 1969), hamster

*Reprint requests to Professor LeGrande C. Ellis. 
(Morton \& Chang, 1973), mouse (Hoppe, 1975) and rabbit (Lambiase \& Amann, 1963; OrgebinCrist, 1967a; Igboeli \& Foote, 1969) to fertilize ova have been well documented. By contrast, spermatozoa from the corpus and cauda epididymidis and the vas deferens do have fertilizing capabilities (Sorgen \& Glass, 1972; Morton \& Chang, 1973; Hoppe, 1975; Orgebin-Crist, 1965, 1967a; Bedford, 1966, 1967). Paufler \& Foote (1968) and Bedford (1967) further showed that retaining the spermatozoa in the caput epididymidis did not give them the capability to fertilize. Bedford (1966) and OrgebinCrist (1967b) both reported that spermatozoa had to have been present in the corpus epididymidis before they could fertilize. Additional reports suggest that, in addition to the ability to fertilize, spermatozoa differ in electrophoretic mobility (Bedford, 1963a) and acrosomal width (Bedford, 1963b) after passing from the caput to the cauda epididymidis.

PGs thus seem necessary for normal fertility in the male. They are present in high concentrations in the semen, but their site of origin is unknown. The available data suggest that arachidonic acid from sperm lipids may be used for PG synthesis (Poulos et al., 1973), but this needs to be verified.

The present study was undertaken to determine the sites of PG synthetase activity within the male reproductive tract, and whether the arachidonic acid reportedly lost in the epididymis is correlated with PG synthetase activity in this organ.

\section{Materials and Methods}

Twelve male rats, 60-210 days of age, were killed by decapitation. Each testis, caput, corpus or cauda epididymidis and vas deferens was removed immediately, weighed and then frozen on solid $\mathrm{CO}_{2}$ until sectioned. The frozen tissues were sectioned $(10 \mu \mathrm{m})$ on a cryostat microtome at $-20^{\circ} \mathrm{C}$. The sections were placed on slides, dried in a stream of nitrogen and then assessed histochemically for PG synthetase activity. Several slides were made of each tissue to facilitate simultaneous incubations with and without substrates and a PG synthesis inhibitor.

The tissues were incubated for $3 \mathrm{~h}$ at $35^{\circ} \mathrm{C}$ in one of three incubation mixtures: (a) $10 \mathrm{ml} 0.2 \mathrm{M}$ -

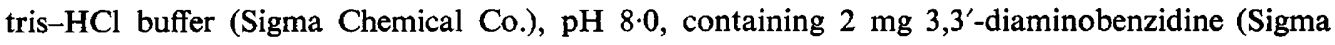
Chemical Co.) and $0.65 \mathrm{mg} \mathrm{KCN}$ (Fisher Scientific Co); (b) the above solution plus $0.4 \mathrm{mg}$ dihomo- $\gamma$ linolenic acid or $0.4 \mathrm{mg}$ arachidonic acid (Applied Science Laboratories); (c) both of the above plus indomethacin (Merk Sharp and Dohme) (Janszen \& Nugteren, 1971). This allowed us to ascertain whether (1) PGs were synthesized from endogenous polyunsaturated fatty acid substrates; (2) PGs were synthesized from endogenous and exogenous substrates (dihomo- $\gamma$-linolenic and arachidonic acids); and (3) indomethacin would inhibit PG synthesis from endogenous and exogenous substrates. After incubation the tissues were rinsed in distilled water and embedded in glycerin jelly.

Two photomicrographs were taken of a given area on a slide-one by using bright-field microscopy and the other with phase-contrast microscopy. The phase-contrast photomicrographs were used to identify cellular detail. The bright-field photomicrographs were used for observations of the areas staining for PG synthetase activity.

Thin sections of rat kidney were incubated as indicated above to determine whether the assay system was functional and reliable.

\section{Results}

Kidney tissue (PI. 1, Fig. 1) showed appreciable brown staining of specific cells for PG synthetase activity. The staining was similar to that reported by Janszen \& Nugteren (1971), indicating that this method was valid in our laboratory. No appreciable PG synthetase activity was observed in seminiferous tubules, the rete testis or the caput epididymidis. There was, however, moderate PG synthetase activity of the spermatozoa within the tubules of the corpus epididymidis, and adipose cells within the adherent fat pads (PI. I, Figs 1B, 1C and 1D). Similarly, the spermatozoa in the epididymal tubules, isolated interstitial cells, cells within the capsule and fat cells in the adipose tissue adhering to the cauda epididymidis all showed brown staining typical of PG synthesis activity (PI. 2, Figs 2A 
PLATE I

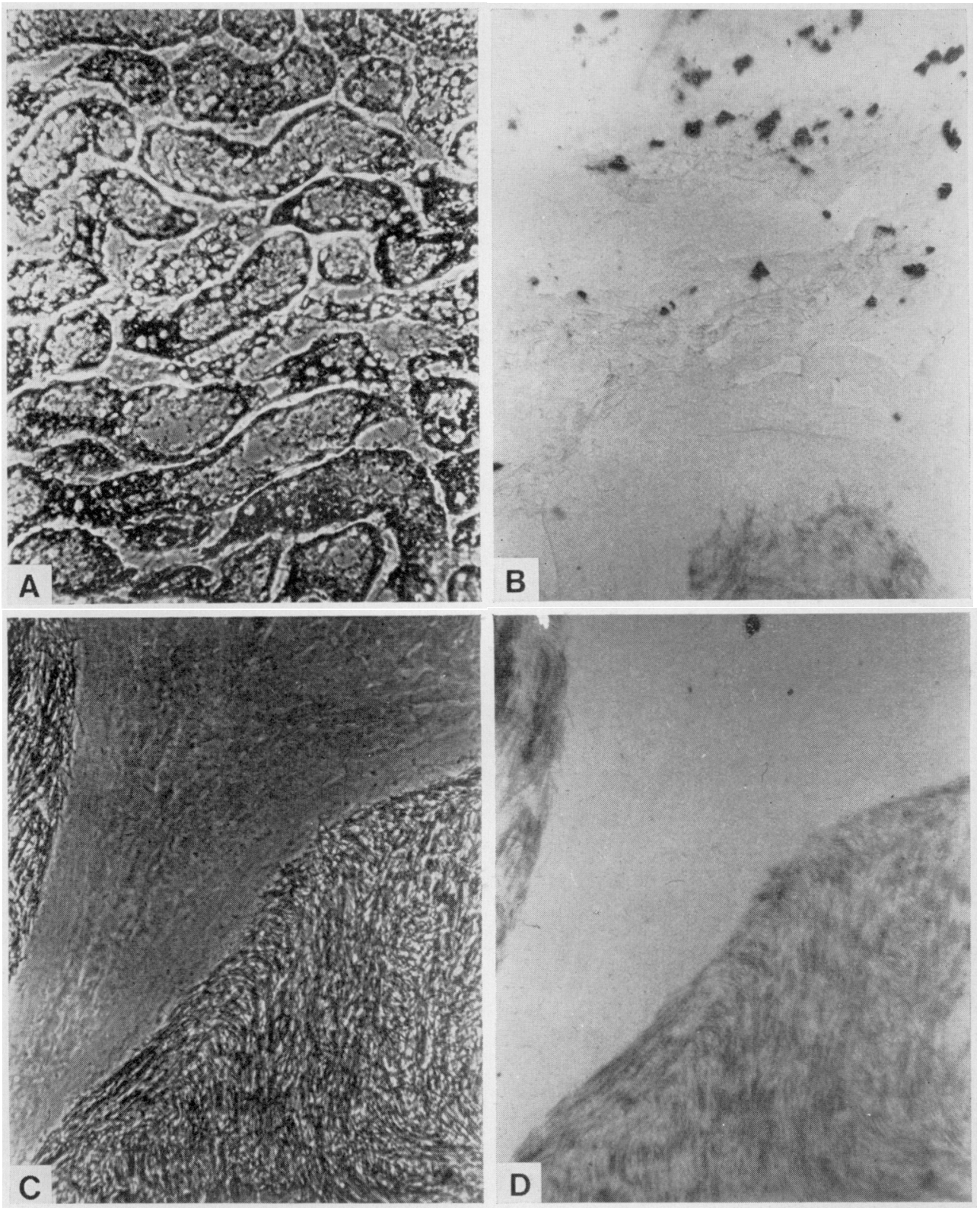

Fig. 1. Histochemical localization of PG synthetase activity in rat kidney and epididymal tisste with arachidonic acid as the substrate. $\times 230$. (A) Bright-field photontcrograph of rat kidnes showing staining for PG synthetase activity at the periphery of the tubules. (B) Bright-field photomicrograph of the corpus epididymidis and adjacent fat pad showing marked staining of individual adipose cells and of sperm tails within the epididymal tubule. $(C$ and $D)$ Phase-contrast and bright-field photomicrographs, respectively. of the corpus epididymidis showing staining of the sperm tats within the epididymal tubules and an occasional interstitial cell. 


\section{PLATE 2}
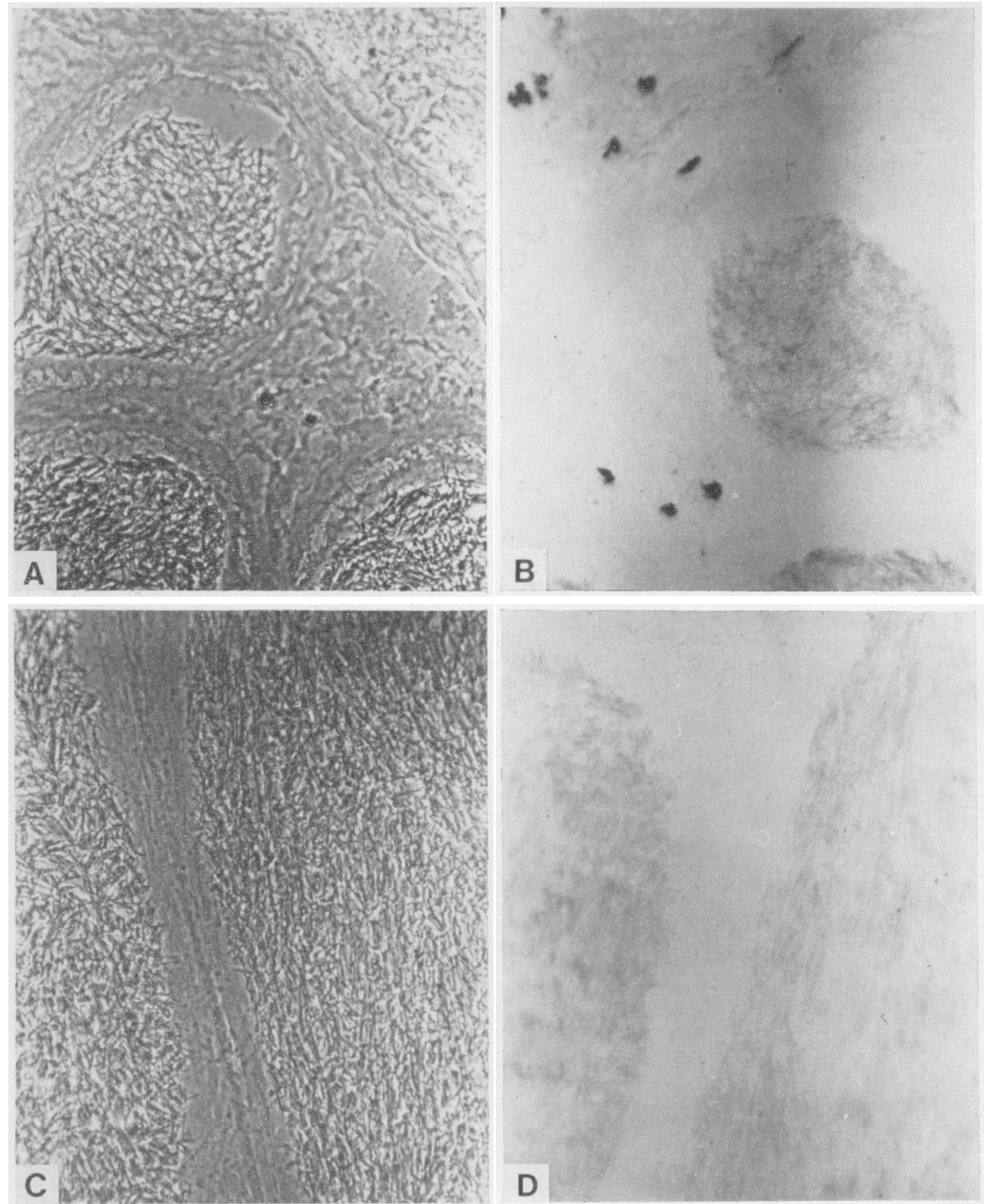

Fig. 2. Histochemical localization of $P G$ synthetase activity in rat epididymis with arachidonic acid as the substrate. $\times 230$. (A and $B$ ) Phase-contrast and bright-field photomicrographs, respectively, of cauda epididymidis showing staining in isolated interstitial cells, sperm tails in the tubules, and isolated cells in the capsule. (C and D) Phase-contrast and bright-field photomicrographs, respectively, of corpus epididymidis with indomethacin showing a reduced staining for PG synthetase activity when compared with either the corpus or the cauda epididymidis without indomethacin. 
PLATE 3
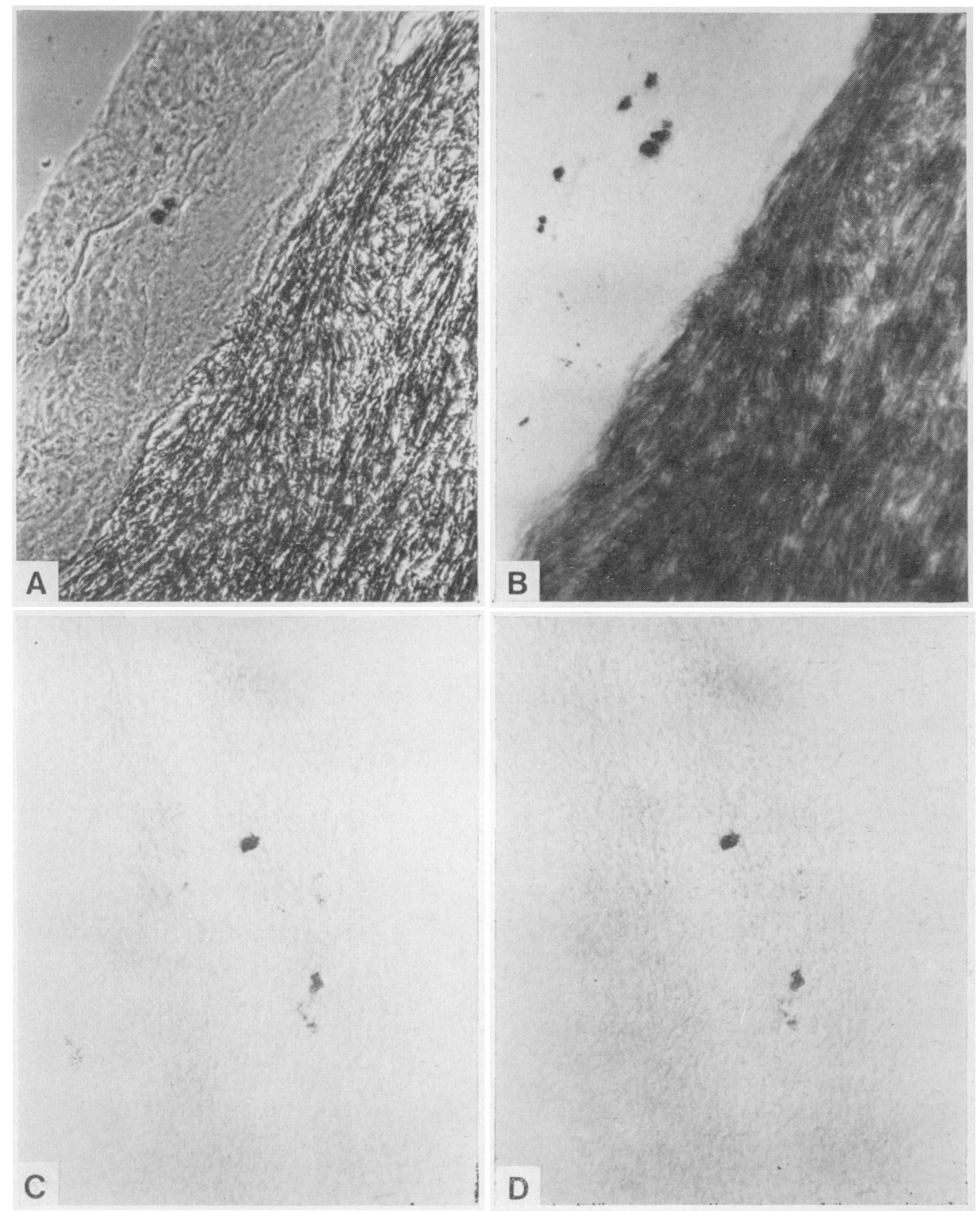

Fig. 3. Localization of $P G$ synthetase activity in rat vas deferens and teased seminiferous tubules with arachidonic acid as the substrate. $\times 230$. ( $\mathrm{A}$ and $\mathrm{B}$ ) Phase-contrast and bright-field photomicrographs, respectively, of vas deferens showing staining of the sperm tails in the lumen and isolated cells in the capsule. (C and D) Phase-contrast and bright-field photomicrographs, respectively, showing general staining associated with the germinal cells within the teased seminiferous tubules, with an occasional isolated cell showing marked activity. 
PLNTI +
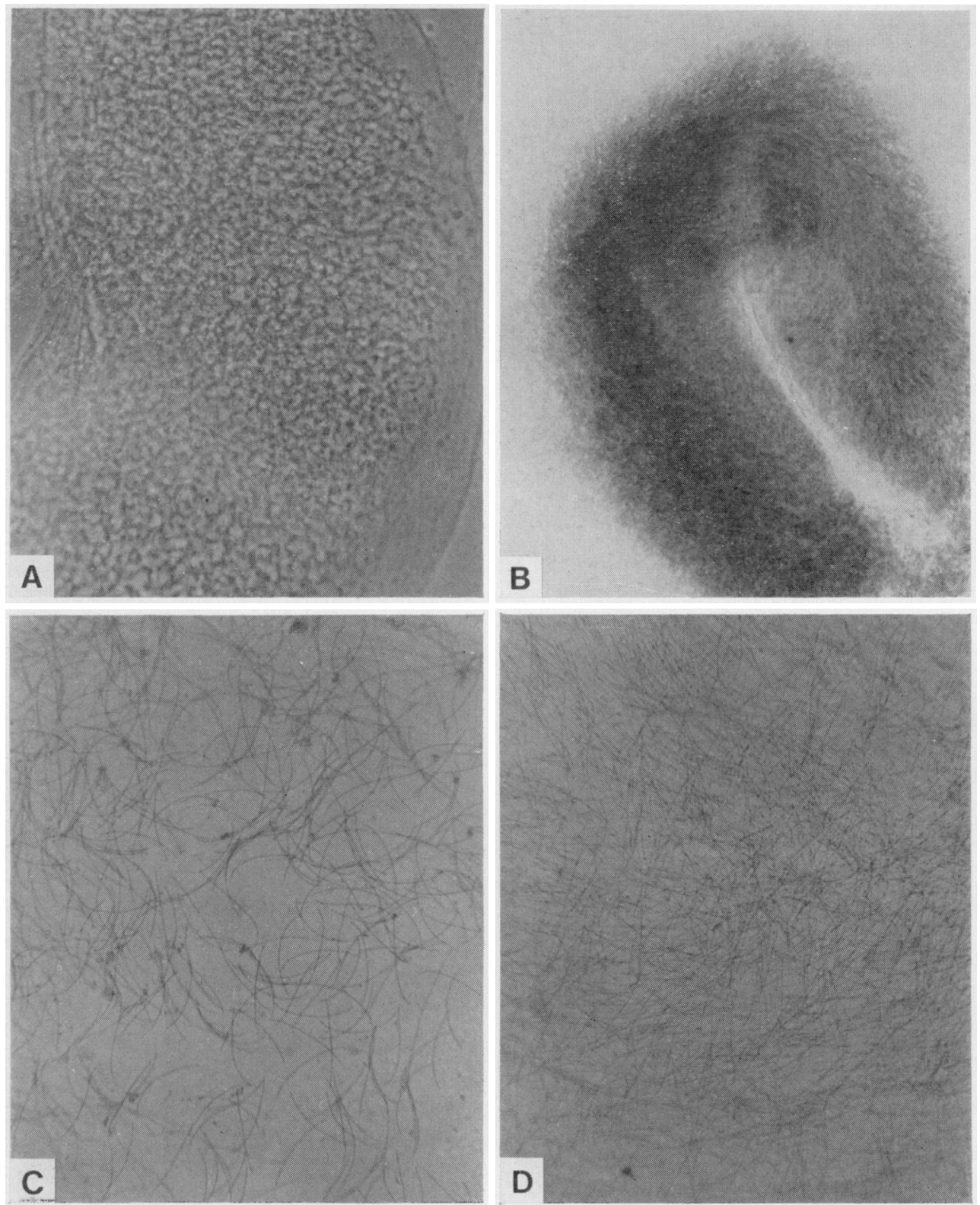

Fig. 4. Localizatton of PG; şnthetase activis within leased seminiferous tubules and spermatozoa taken from the rat epidid! mis with arachidonic acid as the substrate. $\times 230$. (A) Phase-contrast photomicrograph

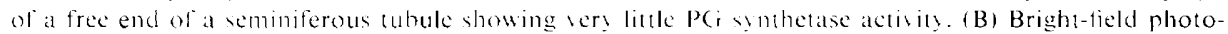
micrograph of a damaged end of a seminiferous tubule showing marked stainingassociated with the germinal celfs within the tubule. $(C)$ Bright-field photomicrograph of spermatoroa taten from the caput epididymidis showing marked staining associated with the sperm tails. (D) Bright-field photomicrograph of spermatozoa shatinad from the callda epidids midis showing marhed staining of the sperm laik. 
and 2B). In addition, fat cells adhering to the testicular capsule, caput epididymidis, and vas deferens (data not shown) all stained positively for PG synthetase activity. Fewer cells in the testicular capsule than in the epididymis or vas deferens, however, exhibited PG synthetase activity. These observations were essentially the same whether dihomo- $\gamma$-linolenic or arachidonic acid was used as the substrate. The addition of indomethacin to the incubation media reduced, but did not totally abolish PG synthetase activity (Pl. 2, Figs $2 \mathrm{C}$ and 2D).

Marked staining for PG synthetase activity was observed for the spermatozoa and isolated capsular cells of the vas deferens (Pl. 3, Figs 3A and 3B). Some generalized staining of teased seminiferous tubules was observed as well as some specifically stained cells (PI. 3, Figs 3C and 3D). Undamaged free ends of teased seminiferous tubules (PI. 4, Fig. 4A) showed little PG synthetase activity while damaged ends showed very marked activity (P1. 4, Fig. 4B).

Only the tails of spermatozoa in the epididymis and vas deferens demonstrated PG synthetase activity (P1. 4, Figs 4C and 4D), Moreover, spermatozoa from the caput epididymidis, although showing no PG synthetase activity while in the tubules (data not shown), did so when removed from the tubules (Pl. 4, Fig. 4C). The above observations suggest that the testis and caput epididymidis may contain an inhibitor which normally suppresses PG synthesis but is circumvented by physical trauma, e.g. when the spermatozoa are removed from the deferent ducts.

Cells that exhibited PG synthetase activity did so with and without exogenous substrate. There was, however, a slight, but not marked, increase in staining when dihomo- $\gamma$-linolenic or arachidonic acid was added to the incubation media, indicating that endogenous substrate was not rate-limiting for PG synthesis under the conditions of this assay.

For tissues that exhibited staining of two or more units (Table 1), the amount of staining was slightly reduced when indomethacin was present in the medium.

Table 1. Relative intensities* of staining of spermatozoa from various tissues within the reproductive system of the male rat

\begin{tabular}{|c|c|c|c|c|c|c|}
\hline \multirow[b]{2}{*}{ Substrate } & \multirow[b]{2}{*}{ Testis } & \multirow{2}{*}{$\begin{array}{c}\text { Rete } \\
\text { tubules }\end{array}$} & \multicolumn{3}{|c|}{ Epididymis } & \multirow{2}{*}{$\begin{array}{c}\text { Vas } \\
\text { deferens }\end{array}$} \\
\hline & & & Caput & Corpus & Cauda & \\
\hline Arachidonic acid & $0-1$ & $0-1$ & $0-1$ & $2-5$ & $5-7$ & $8-10$ \\
\hline Dihomo- $\gamma$-linolenic acid & $0-1$ & $0-1$ & $0-1$ & $2-5$ & $5-7$ & $8-10$ \\
\hline None & $0-1$ & $0-1$ & $0-1$ & $2-5$ & $5-7$ & $8-10$ \\
\hline Indomethacin & $0-1$ & $0-1$ & $0-1$ & $1-4$ & $4-6$ & $7-8$ \\
\hline
\end{tabular}

* The scale is arbitrary with 10 being the most intense and 0 showing no staining.

\section{Discussion}

Although PGs were first observed in human semen (see Horton, 1972), their origin and role in male reproduction remain largely unknown. While PGs occur in substantial quantities in human, bull and ram semen, they are much less common in the semen of some other animals (Cenedella, 1975). The appearance of $P G$ synthetase activity in the corpus and cauda epididymidis and vas deferens of various species is consistent with observations that relatively large amounts of arachidonic acid are released from the spermatozoa as they migrate through the reproductive tracts of bulls (Poulos $e t$ al., 1973), rams (Poulos et al., 1975) and monkeys (Arora et al., 1975). Our data corroborate the conclusions that: spermatozoa themselves are the source of seminal PGs (Poulos et al., 1975; Marley \& Smith, 1975); PGs play a functional role in the maturation process of the male gamete as it passes through the epididymis and the vas deferens (Poulos et al., 1973); and PGs are produced in the lumen of the tubules of the epididymis rather than by the epididymis itself (Badr et al., 1975; Marley \& Smith, 1975). The failure of exogenous substrate (arachidonic and dihomo- $\gamma$-linolenic acid) to increase PG synthesis markedly suggests that there is adequate endogenous substrate for PG synthesis, as suggested by the observations of Poulos et al. $(1973,1975)$ and Arora et al. (1975). Our data also 
suggest a functional role for the arachidonic acid that is normally released from the sperm membranes as the germ cells pass through the epididymis. Boccio (1977) has shown that there is a membrane phospholipase $\mathrm{A}_{2}$ with an alkaline $\mathrm{pH}$ optimum which is associated with rat germinal epithelium and appears to be specific for the mobilization of unsaturated fatty acids (arachidonic acid) from membrane phospholipids. It is possible that endogenous fatty acids are more important for PG synthesis than are exogenous fatty acids. Since the PG synthetase activity that we observed was also associated with the membranes of the germinal cells, it is possible that there is a direct transfer of arachidonic acid from the membrane to the PG synthetase enzyme system. This would explain why exogenous arachidonic acid does not appreciably increase PG synthesis in the male reproductive tract.

The possibility that the staining observed in this investigation may result from catalase-type reactions can be ruled out because $\mathrm{KCN}$ was added to the incubation media and this compound specifically inhibits these reactions (Janszen \& Nugteren, 1971). It is quite possible that the staining may be due to peroxidation of unsaturated fatty acids (particularly arachidonic acid) because endoperoxides are intermediates in the synthesis of PGs (for reviews see Ellis \& Baptista, 1969, Ellis, Sorenson \& Buhrley, 1975; Ellis \& Hargrove, 1977). Our data suggest that the staining of the seminiferous tubules is not due to disruption of the tubule by ice crystal formation and the subsequent diffusion of the diaminobenzidine into the tube (i.e. the unstained areas are those which are intact and into which the dye has not penetrated), because the piece of tubule that was not stained (Pl. 4, Fig. 4A) was the open end of a tubule into which the dye could easily have penetrated. Moreover, we have observed (data not shown) that where the ends of tubules are stretched and damaged during the teasing process there is marked staining whereas the undamaged areas show very little staining.

We have found (unpublished) a similar histochemical localization pattern of PG synthetase activity in the male reproductive tract of other animals. Differences in the absolute amounts of PGs in the semen could be due to contributions from the seminal vesicles or the prostate or both, but some PGs are produced by the spermatozoa. This synthesis is low in the testis and the caput epididymidis but is maximal in the vas deferens. Our data thus corroborate the conclusion of Marley \& Smith (1975) that the PG-like substances present in rat semen at the time of mating have their origin in the vas deferens.

During maturation of epididymal spermatozoa there is a conversion of sulphydryl groups to disulphur bridges in the nucleus and tail structures (Prasad et al., 1974) which are said to lead to stabilization of the chromatin material and alterations in permeability. PGs result from the peroxidation of arachidonic acid to give the corresponding endoperoxides which can take protons from sulphydryl groups, thereby converting them to a disulphur bridge. The endoperoxides are converted in the epididymis primarily into PGE-2 (for reviews see Ellis \& Baptista, 1969; Ellis et al., 1975; Ellis \& Hargrove, 1977) which in turn could activate adenyl cyclase (Seeley, Hargrove, Sanders \& Ellis, 1974) and thereby increase sperm cAMP, as has been reported for hamster spermatozoa (Hoskins \& Casillas, 1975). The cyclic nucleotides reportedly enhance the metabolism and motility of the spermatozoa (for review see Hoskins \& Casillas, 1975). The low levels of PG synthetase activity in rat seminiferous tubules is consistent with the observation that aspirin and indomethacin (both inhibitors of PG synthesis) increase the number of germinal cells in mouse testes (Abbatiello, Kaminsky \& Weisbroth, 1975).

The above data are also consistent with the observation that exogenous PGs are deleterious to the testis (for reviews see Cenedella, 1975; Ellis \& Hargrove, 1977) and that aspirin localizes and ameliorates the damage to the testis resulting from physical trauma (Raitsina, Delektorskii, Gladkovia \& Davydova, 1975). Moreover, activation of PG synthesis may be very important as a mediator of certain types of damage to the germinal epithelium of the male gonad (Prasad et al., 1974).

The low levels of PG synthetase activity in the testis and for spermatozoa in the caput epididymidis (even in the presence of exogenous substrate) was markedly increased when the cells were removed from this structure). This change implies the existence of an inhibitor of PG synthesis which is removed in the caput and possibly in the corpus and cauda epididymidis. The inability of indomethacin to totally efface PG synthetase activity is consistent with the observation that this inhibitor of PG synthesis was only partly able to inhibit the contractility of rat seminiferous tubules, another 
known PG-dependent phenomenon (Buhrley \& Ellis, 1975). This lack of inhibition can be explained in part by the difficulty that indomethacin has in penetrating membranes (Raz, Stern \& KenigWakshal, 1973).

We thank Gary L. Kelley and Dr Nabil N. Youssef for their help and assistance with the photomicrographs and Dr Horace D. Brown of Merk Sharp and Dohme for the generous gift of indomethacin. This work was sponsored by USERDA Grant No. E (11-1)-1602 and Utah State University Research Project No. U-300, and was submitted as partial fulfilment of the requirement for the M.S. degree in Physiology at Utah State University, Logan, Utah.

\section{References}

Abbatiello, E.R., Kaminsky, M. \& Weisbroth, S. (1975) The effects of prostaglandin inhibitors on spermatogenesis. Int. J. Fert. 20, 177-182.

AMANN, R.P. \& GRIEL, L.C. (1974) Fertility of bovine spermatozoa from rete testes, cauda epididymis and ejaculated semen. J. Dairy Sci. 57, 212-219.

Arora, R., Dinaker, N. \& Prasad, M.R.N. (1975) Biochemical changes in the spermatozoa and luminal contents of different regions of the epididymis of the Rhesus monkey, Macaca mulatta. Contraception 11, 689-700.

BADR, F.M., Barcikowski, B. \& Bartke, A. (1975) Effect of castration, testosterone treatment and hereditary sterility on prostaglandin concentration in the male reproductive system of mice. Prostaglandins 9, 289-298.

BEDFORD, J.M. (1963a) Changes in electrophoretic properties of rabbit spermatozoa during passage through the epididymis. Nature, Lond. 200, 11781180.

BEDFORD, J.M. (1963b) Morphological changes in rabbit spermatozoa during passage through the epididymis. J. Reprod. Fert. 5, 169-177.

BEDFORD, J.M. (1966) Development of the fertilizing ability of spermatozoa in the epididymis of the rabbit. J. exp. Zool. 163, 319-325.

BEdFoRD, J.M. (1967) Effects of duct ligation on the fertilizing ability of spermatozoa from different regions of the rabbit epididymis. J. exp. Zool. 166, 271-282.

Boccio, J.R. (1977) The localization and partial characterization of rat testicular phospholipase $A_{2}$. M.S. Thesis, Utah State University, Logan, Utah.

Brummer, H.C. \& Gillespie, A. (1972) Seminal prostaglandins and fertility. Clin. Endocr. 1, 363368.

BuHRLey, L.E. \& Ellis, L.C. (1975) Contractility of rat testicular seminiferous tubules in vitro: prostaglandin $F_{1} \alpha$ and indomethacin, Prostaglandins 10, 151-162.

Bygdeman, M. (1969) Prostaglandins in human seminal fluid and their relation to fertility. Int. J. Fert. 14, 228-231.

Bygdeman, M. \& Samuelsson, B. (1966) Analysis of prostaglandins in human semen. Prostaglandins and related factors. Clin. chim. Acta 13, 465-474.

Bygdeman, M., Svanborg, K. \& Samuelsson, B. (1969) A method for determination of prostaglandins in human seminal fluid. Clin. chim. Acta 26, 373-379.

Cenedella, R.J. (1975) Prostaglandins and male reproductive physiology. In Molecular Mechanisms of Gonadal Hormone Action, pp. 325-358. Eds J. A. Thomas and R. L. Singhal. University Park Press, Baltimore.

Ellis, L.C. \& Baptista, M.H. (1969) A proposed mechanism for the differential radiosensitivity of the immature rat testis. In Radiation Biology of the Juvenile Mammal, pp. 963-974. Eds M. R. Sikov and D. D. Mahlum. U.S. Atomic Energy Commission, Division of Technical Information, Oak Ridge.

Ellis, L.C. \& Hargrove, J.L. (1977) Prostaglandins. In The Testis, Vol. 6, pp. 289-313. Eds A. D. Johnson, W. R. Gomes and N. L. VanDemark. Academic Press, New York.

Ellis, L.C., Sorenson, D.K. \& Buhrley, L.E. (1975) Mechanisms and interactions in testicular steroidogenesis and prostaglandin synthesis. J. Steroid Biochem. 6, 1081-1090.

Hamberg, M. \& Samuelsson, B. (1966) Prostaglandins in human seminal plasma: prostaglandins and related factors. J. biol. Chem. 241, 254-263.

HAwkins, D.F. (1967) Relevance of prostaglandins to problems of human subfertility. In Prostaglandin Symposium of the Worcester Foundation for Experimental Biology, pp. 1-10. Eds P. W. Ramwell and J. E. Shaw. Interscience Publishers, New York.

HopPe, P.C. (1975) Fertilizing ability of mouse sperm from different epididymal regions and after washing and centrifugation. J. exp. Zool. 192, 219-222.

Horton, E.W. (1972) Prostaglandins, p. 197. SpringerVerlag, New York.

Hoskins, D.D. \& Casillas, E.R. (1975) Hormones, second messengers, and the mammalian spermatozoan, In Molecular Mechanisms of Gonadal Hormone Action, pp. 283-324. Eds J. A. Thomas and R. L. Singhal. University Park Press, Baltimore.

IgBoELI, G. \& FoOte, R.H. (1969) Maturation and aging changes in rabbit spermatozoa isolated by ligation at different levels of the epididymis. Fert. Steril. 20, 506-520.

JANSzeN, F.H.A. \& Nugteren, D.H. (1971) Histochemical localization of prostaglandin synthetase. Histochemistry 27, 159-164.

LAmbiase, J.T. \& AMANN, R.P. (1963) Infertility of rabbit testicular spermatozoa in their native environment. Fert. Steril. 24, 65-67.

Marley, P.B. \& Smith, C.C. (1975) Production of prostaglandin-like substance at the time of mating in the rat. Prostaglandins 10, 435-441. 
Morton, B. \& Chang, T.S.K. (1973) The effect of fluid from the cauda epididymidis, serum components and caffein upon the survival of diluted epididymal hamster spermatozoa. J. Reprod. Fert. 35, 255-263.

Neill, A.R. \& Masters, C.J. (1972) Metabolism of fatty acids by bovine spermatozoa. Biochem. J. 127, 375-385.

Nishikawa, Y. \& Waide, Y. (1952) Studies on the maturation of spermatozoa. 1. Mechanism and speed of transition of spermatozoa in the epididymis and their functional changes. Bull. natn. Inst. agric. Sci., Tokyo, Ser. G, 3, 69-81.

ORGebiN-CrIST, M.-C. (1965) Passage of spermatozoa labelled with thymidine- ${ }^{3} \mathrm{H}$ through the ductus epididymis of the rabbit. J. Reprod. Fert. 10, 241-251.

ORGEBIN-CRIST, M.-C. (1967a) Sperm maturation in the rabbit epididymis. Nature, Lond. 216, 816-818.

ORGEBIN-CRIST, M.-C. (1967b) Maturation of spermatozoa in the rabbit epididymis. Fertilizing ability and embryonic mortality in does inseminated with epididymal spermatozoa. Annls Biol. anim. Biochim. Biophys. 7, 373-389.

Paufler, S.K. \& Foote, R.H. (1968) Morphology, motility and fertility of spermatozoa recovered from different areas of ligated rabbit epididymides. $J$. Reprod. Fert. 17, 125-137.

Poulos, A., Voglmayr, J.K. \& White, I.G. (1973) Phospholipid changes in spermatozoa during passage through the genital tract of the bull. Biochim. biophys. Acta 306, 194-202.

Poulos, A., Brown-Woodman, P.D.C., White, I.G. \& Cox, R.I. (1975) Changes in phospholipids of ram spermatozoa during migration through the epididymis and possible origin of prostaglandin $F_{2} \alpha$ in testicular and epididymal fluid. Biochim. biophys. Acta 388, 12-18.
Prasad, M.R.N., Rajalakshmi, M., Gupta, G., Dinaker, N., Arora, R. \& KarkUN, T. (1974) Epididymal environment and maturation of spermatozoa. In Male Fertility and Sterility, pp. 459-478. Eds R. E. Mancini and L. Martini. Academic Press, San Francisco.

Raitsina, S.S., DelektorskiI, V.V., Gladkovia, N.S. \& Davydova, A.I. (1975) Prevention of development of post-trauma atrophy of the rat testis by injection of aspirin. Bull. exp. Biol. Med. U.S.S.R. 78, 1181-1184.

Raz, A., Stern, H. \& Kenig-Warshal, R. (1973) Indomethacin and aspirin inhibition of prostaglandin $E_{2}$ synthesis by sheep vesicles, microsome power and seminal vesicles. Prostaglandins 3, 337352.

SASAMORI, S. (1965) Isolation of prostaglandins from human seminal fluid and studies on their stimulating effects on smooth muscle. Sapporo med.J. 28, 286299.

Sefley, R.R., Hargrove, J.L., Sanders, R.T. \& Ellis, L.C. (1974) Rabbit testicular capsular contractionsprostaglandins, cyclic adenosine 3',5-monophosphate and epinephrine. Biochem. Pharmacol. 23, 29692976.

Setchell, B.P., Scott, T.W., Voglmayr, J.K. \& WAITES, G.M.H. (1969) Characteristics of testicular spermatozoa and the fluid which transports them into the epididymis. Biol. Reprod., Suppl. 1, 40-66.

SoRgen, C.D. \& Glass, R.H. (1972) Lack of effect of prostaglandin $F_{2} \alpha$ on the fertilizing capacity of rabbit sperm. Prostaglandins 1, 229-233.

Voglmayr, J.K. (1973) Prostaglandin $F_{2} \alpha$ concentration in genital tract secretions of dairy bulls. Prostaglandins 4, 673-678. 